\title{
The Association between Openness and Physiological Responses to
}

\section{Recurrent Social Stress}

\begin{abstract}
The association between openness (assessed by shortened Chinese version of NEO Five-Factor Inventory, NEO-FFI) and physiological reactivity to, and recovery from, social stress (a video-recorded, timed public speaking task with evaluators present in the room), and physiological adaptation to repeated social stress was examined in the present study. Subjective and physiological data were collected from 70 college students across five laboratory stages: baseline, stress exposure period 1, post-stress period 1, stress exposure period 2, and post-stress period 2. Results indicated that higher openness was associated with lesser heart rate (HR) reactivity to the first and second stress exposure, and lesser systolic blood pressure (SBP) reactivity to the second stress exposure. Higher openness was associated with higher resting respiratory sinus arrhythmia (RSA), lesser RSA withdrawals to the first stress exposure, and more complete RSA recovery after the first stress exposure. Moreover, higher openness was associated with pronounced systolic and diastolic blood pressure (SBP, DBP) adaptation with greater decreases in SBP and DBP reactivity across the two successive stress exposures. These findings might shed light on the biological basis linking openness to health.
\end{abstract}

Keywords: openness, social stress, physiological reactivity, physiological recovery, physiological adaptation 
Openness refers to a variety of tendencies including curiosity, appreciation for complexity, a desire for variety, esthetic appreciation, imagination and fantasy, and non-traditional values (Connelly, Ones, Davies, \& Birkland, 2014; Costa \& McCrae, 1992). Individuals with different levels of openness have distinct social adaptation, mental health, and physical health outcomes. Accumulating studies have shown that high openness is an independent and protective factor associated with improved concurrent and future health prospects (Jonassaint et al., 2007; Lee et al., 2014; Taylor et al., 2009). Individuals high in openness are generally more resilient, find novelty more rewarding than familiarity, and are effective in coping with interpersonal stress (Lee-Baggley, Preece, \& DeLongis., 2005; Shiner \& Masten, 2012). The behavioral response agility inherent in such a trait may also be reflected in the autonomic nervous system responses (Čukič \& Bates, 2014, Williams, Rau, Cribbet, \& Gunn 2009), and the way openness influence physiological responses to social stressors might duly influence associated health processes. Recently, Williams et al. (2009) found higher openness to be associated with increases in parasympathetic activity, and with lesser cardiovascular reactivity to social stress (operationalized as a social competence interview). However, whether their findings can be replicated in other type of social stress among participants of other cultural backgrounds remains an open question. Notably, a number of studies have suggested that the way physiological responses habituate across repeated stressors might further elucidate different adaptation and health consequences (al'Absi et al., 1997; Hughes, Howard, James, \& Higgins, 2011; McEwen, 1998; Kelsey, 1991, 1993; Kelsey et al., 1999, 2000). The role of openness in shaping patterns of physiological habituation across recurrent social stressors has yet to be identified. Therefore, 
these two issues were addressed in the present study.

Previous studies suggest that the magnitude, pattern, and/or duration of physiological responses to stress might be related to different health consequences (James, Gregg, Matyas, Hughes, \& Howard 2012; Schneiderman, Ironson, \& Siegel, 2005). In the main, this research has suggested that moderate (i.e., neither exaggerate nor blunted) cardiovascular reactivity to stress (Allen, 2013; Chida \& Steptoe, 2010; Manuck, 1994; Obrist, 1976; Phillips, Ginty, \& Hughes, 2013; Treiber et al., 2003), as well as efficient cardiovascular recovery after stress (Haynes, Gannon, Orimoto, O’Brien, \& Brandt, 1991; Pieper \& Brosschot, 2005) are most likely to underlie healthful physiological outcomes. In addition, respiratory sinus arrhythmia (RSA), which refers to the variability in heart rate that corresponds to changes in respiration, has received much attention from researchers as a physiological marker of stress regulation (Berntson et al., 1997; Grossman \& Taylor, 2007). High resting RSA, modest reductions in RSA (i.e., RSA withdrawals) under stress, and efficient physiological recovery after stress each indicates better social and emotional competence and adaptive regulation (Porges, 2007; Thayer \& Lane, 2000; Santucci et al., 2008). Adaptive physiological outcomes have also been associated with physiological adaptation to repeated stress. Adaptation (or habituation) is most simply computed as a decreased response to a repeated stimulus (Eisenstein, Eisenstein, \& Smith, 2001). Pronounced physiological adaptation to repeated stress may represent one's ability to cope successfully with an adverse stimulus (al'Absi et al., 1997; Bremner, Southwick, \& Charney, 1995; Frankish \& Linden, 1991; Kelsey, 1991, 1993; Kelsey et al., 1999, 2000), whereas lack of adaptation may reflect an inability to adapt, and so may possibly lead to health problems (Hughes et al., 2011; McEwen, 1998) and serve as a 
physiological marker of anxiety vulnerability (Turner, Beidel, \& Robertson-Nay, 2005).

As mentioned above, individuals high in openness are believed to favor novel challenges and cope effectively with interpersonal events. A number of researchers have thus sought to examine associated patterns of physiological responses, albeit producing mixed findings. Bibbey et al. (2013) reported that higher openness was related to greater cardiovascular reactivity to a series of stressors (Stroop, mental arithmetic, mirror tracing, and speech); Jonassaint et al. (2010) found persons high in openness to exhibit lower levels of C-reactive protein in response to mental arithmetic; Čukič and Bates (2014) failed to find any relationship between openness and sympathetic or parasympathetic autonomic activity during cognitive stress (mental arithmetic task and Stroop task). These mixed findings may be due to the fact that the nature of stressors was not identical across the studies. Social stress (such as that induced by public speaking or social competence interviews) is likely to differ from cognitive stress (such as that induced by mental arithmetic or Stroop tasks) in its effects on physiological activity (al'Absi et al., 1997; Pertaub, Slater, \& Barker, 2002; Slater, Pertaub, Barker, \& Clark, 2006; Westenberg et al., 2009). Openness, as a typical trait involving social dimensions, might be of particular relevance to social stress. As noted previously, Williams et al. (2009) examined the physiological responses of openness to social stress, and found that higher openness was associated with increases in RSA and lesser cardiovascular (SBP, DBP) reactivity during a social competence interview task. However, it is unknown that whether the findings of Williams et al. (2009) can be replicated in other types of social stress, such as socially evaluative stress (a type of social stress that elicits considerable emotional challenges, as well as cardiovascular stress responses; Hofmann, 2006). Therefore, one aim of the present 
study was to examine this issue.

Additionally, existing studies have found that purportedly maladaptive personality characteristics, such as neuroticism, trait rumination, type D personality, and trait dominance (Hughes et al., 2011; Johnson et al., 2012; Howard \& Hughes, 2013; Lee \& Hughes, 2014) are positively related to disrupted or dampened physiological adaptation, which might in turn result underlie psychosomatic processes. Comparatively, purportedly adaptive personality characteristics such as low neuroticism, non-type D personality, or high openness, may be related to better physiological adaptation to repeated stress, and so be beneficial to health outcomes. However, no study to date has examined the impact of openness on physiological adaptation to repeated stress. This issue was also addressed in the present study.

In summary, while there are sound conceptual reasons to predict that openness promotes health by assisting stress adaptation, our understanding of how openness is associated with physiological responses to social stress, especially to recurrent social stress, is currently limited. The present study was to investigate the association between openness and physiological reactivity, physiological recovery, and physiological adaptation to repeated socially evaluative stress (public speaking) among Chinese college students. Based on existing findings, it was hypothesized that higher levels of openness would be associated with lesser physiological reactivity to social stress, more complete physiological recovery after social stress, and more pronounced physiological adaptation to repeated social stress.

\section{Method}

\section{Participants}

Seventy sophomore students were eligible to take part in our study (45 female; $\mathrm{M}_{\text {age }}=$ 
19.23 years, $\mathrm{SD}=0.78 ; 98 \%$ Han nationality). All of them were normotensive (resting SBP of 90 to $140 \mathrm{mmHg}$ and/or resting DBP of 60 to $90 \mathrm{mmHg}$ ), and physically healthy (reporting no diagnoses of diabetes mellitus, hypertension, hyperlipaemia, renal or hepatic dysfunction, no history of cardiovascular disease, and no history of alcohol or drug abuse within the last 6 months).

\section{Measures}

Openness. Openness was assessed using the shortened Chinese version of Costa and McCrae's (1992) NEO-FFI, which contained five 12-item scales and showed good reliability and validity on the Chinese sample (Yang et al., 1999). In the present study, Cronbach's alpha was 0.82 for openness.

Socially evaluative stress. In the present study, social stress was induced using speech tasks, which were designed based on the subtask (speech) of the Trier Social Stress Test (TSST) as employed in past research (e.g., Hofmann, 2006; Jonsson et al., 2010; Weeks \& Zoccola, 2015). Participants were given $30 \mathrm{sec}$ to prepare a 5-min speech about a hypothetical scenario in which they had to verbally defend themselves against the threat of unemployment to two confederates. The hypothetical scenarios included "finding a job in high school as a teacher" and "finding a job as an office secretary", reflecting the most popular job positions sought by college-aged participants in the sampling population. Both scenarios were shown to elicit comparable subjective and physiological responses in our pre-experiments. Participants were asked to speak for the full 5-min and refrain from using any hand gestures. If the participant stopped speaking before the 5-min period was up, one committee member said "Please continue, I will tell you when your time is up". If participants were unable to speak 
spontaneously, they were prompted with a series of standard questions to continue speaking (e.g., "Do you have any previous experiences of the specific kind of job?"). The majority of participants were able to deliver the speech without prompts or with no more than one prompt. Participants were informed their speech would be videotaped and later evaluated by expert judges for both content and quality. The two confederates maintained neutral facial expressions and avoided smiling and nodding during the stress task. Across the two consecutive stressors, the assignment of the two hypothetical scenarios was counterbalanced between participants.

Physiological measures. Physiological data were recorded by an integrated system and software package (Biopac MP150, AcqKnowledge; Biopac System Inc., 42 Aero Camino, Goleta, CA 93117, USA). The ECG data were amplified using a Biopac ECG100 electrocardiogram amplifier and collected from participants using $3 \mathrm{Ag}-\mathrm{AgCl}$ disposable electrodes placed in the standard lead II configuration. The Biopac ECG100C amplifier used a band-pass filter of $35 \mathrm{~Hz}$ and $0.5 \mathrm{~Hz}$, sampling at $1000 \mathrm{~Hz}$. Continuous non-invasive beat-to-beat blood pressure was recorded by CNAPTM monitor 500 (CNAPTM Monitor 500; CNSystems Medizintechnik AG, Graz, Austria). The CNAPTM 500 devices were attached to the participant with a CNAPTM finger cuff placed on the second and third digit of one hand, and a calibrating noninvasive BP (NIBP) cuff placed on the upper arm in the same side. The CNAPTM monitor was set to obtain single beat detection from the infrared sensor located in the finger cuff (Saugel, Dueck, \& Wagner, 2014; Winklewski et al., 2015). Systolic (SBP) and diastolic (DBP) blood pressure values were captured every minute for analysis from the CNAP device. The raw data were given in a standard Excel spreadsheet and were calculated 
to obtain the average SBP and DBP values for each study phase. The raw ECG data were first inspected using a template matching function and then visually inspected to delete artifacts and ectopic beats. The time series of identified R-wave were converted to interbeat intervals (IBIs) and sampled at $4 \mathrm{~Hz}$ (with interpolation) to produce equal time intervals (Lü, Wang, \& Liu, 2013). The prorated IBI data were then linearly detrended, end-tapered, and submitted to a fast Fourier transformation method with a Hamming window according to procedures outlined by Berntson et al. (1997). RSA was quantified via a high frequency of the IBI's power spectrum corresponding to the respiratory cycle $(0.15-0.40 \mathrm{~Hz}$; Berntson et al., 1997). High-frequency power values were transformed via a natural logarithm to normalize the distribution yielding unit of $\ln \left(\mathrm{ms}^{2}\right)$ (Wang, Lü, \& Qin, 2013). RSA estimates were calculated sequentially over several short time epochs (1 min for each epoch) (Task Force of the European Society of Cardiology and the North American Society of Pacing and Electrophysiology, 1996), and then were averaged to provide mean RSA levels for each experimental period.

During the experiment, the ECG, systolic and diastolic blood pressure data were measured continuously. HR, RSA, SBP, DBP collected during each 5-min period (baseline, stress exposure period 1, post-stress period 1, stress exposure period 2, and post-stress period 2) were averaged to provide mean HR, RSA, SBP, DBP levels for each experimental period.

\section{Procedure}

Participants were asked to sleep well the night before the study and to refrain from taking any drugs (including caffeine and nicotine) for $2 \mathrm{~h}$ prior to the study. This step was performed to rule out any exogenous effects on the physiological measures. After providing 
informed consent, the ECG recording electrodes and CNAPTM 500 devices were attached to participants, and they were given 10-min to acclimate to the laboratory. Then the physiological experiment session was initiated by a 5-min rest period (baseline), during which participant was instructed to sit, relax, and look at the neutral picture (a picture of a cup drawn from the International Affective Picture System, IAPS; Lang, Bradley, \& Cuthbert, 2005), after which they completed the State Anxiety Inventory (SAI; Wang, Wang, \& Ma, 1999). After the baseline period, the two confederates entered the experiment room and explained the task as follows: "Now, you have an interview for finding a job as a high school teacher. You are allowed $30 \mathrm{sec}$ to make a preparation, and then you have 5-min to state the reason why you are qualified for this job. Your performances will be videotaped and then be evaluated by the researcher for overall content, clarity, and delivery." After $30 \mathrm{sec}$ of preparation, participants engaged in a 5-min social stress task (stress exposure period 1), followed by completing the SAI. After the speech, the two confederates left the room, and participants were given 5-min to rest (post-stress period 1), during which participant was instructed to look at the neutral picture (a picture of an umbrella, from the IAPS), followed again by completing the SAI. Then, the two confederates re-entered the experiment room again and explained the task as follows: "Now, you have an interview for finding a job as an office secretary....." (the other instructions were the same to the first task. The assignment of the two hypothetical scenarios across two successive stressors was counterbalanced between participants). After $30 \mathrm{sec}$ of preparation, participants engaged in a 5-min social stress task (stress exposure period 2), followed by completing the SAI. After the speech, the two confederates left the room, and participants were given 5-min to rest (post-stress period 
2), during which participant was instructed to look at the neutral picture (a picture of a book, from the IAPS), followed by completing the SAI. During the entire experiment, participant's ECG and blood pressure were continuously monitored.

\section{Data reduction}

Based on previous data reduction rationales (e.g., Llabre, Spitzer, Saab, Ironson, \& Schneiderman, 1991), physiological reactivity was calculated as the arithmetic difference between measures taken during the stress exposure period and the immediately preceding baseline (or resting) period (i.e., HR, SBP, DBP reactivity were calculated by subtracting the average preceding resting value from the average stress exposure period value; RSA reactivity was calculated by subtracting the average stress exposure period value from the average preceding resting value). Physiological recovery was calculated as the arithmetic difference between measures taken during the post-stress period and the immediately preceding baseline (or resting) period (i.e., HR, SBP, DBP recovery were calculated by subtracting the average preceding resting value from the average post-stress period value; RSA recovery was calculated by subtracting the average post-stress period value from the average preceding resting value). Physiological adaptation (or habituation) was calculated by subtracting physiological reactivity 2 from physiological reactivity 1 (adaptation was demonstrated by 0 to positive values while lack of adaptation was evident on negative values).

\section{Statistical strategy}

Separate repeated-measures ANOVAs with experimental phase entered as the within subjects factor were performed to determine whether the stressor effectively elicited the 
expected stressful experience and physiological activation. The degrees of freedom and the $F$, $p$ and $\eta^{2}$ values were adjusted using Greenhouse-Geisser correction when sphericity assumptions were not met. Then, the association between openness and physiological variables was preliminarily examined using Pearson correlation analysis. Based on the correlation results, separate hierarchical regressions were conducted with demographic variables (gender, age, father's monthly income, mother's monthly income, father's education level, and mother's education level) entered as control variables, openness entered as predictors, and physiological parameters serving as dependent variables. A colinearity diagnostic was included in each of the regressions, and it indicated that there was no overlap among the demographic variables and openness (tolerance values were 0.20-0.95).

\section{Results}

2.1. Social stress effect on subjective and physiological responses

The means and standard deviations of the subjective and physiological values at the baseline, stress exposure period 1, post-stress period 1, stress exposure period 2, post-stress period 2 are presented in Table 1.

\section{INSERT TABLE 1 HERE}

The repeated measures ANOVA for anxiety across phases (baseline, stress exposure period 1, post-stress period 1, stress exposure period 2, post-stress period 2) indicated a significant main effect for phase $\left(F[3.24,223.63]=32.99, p<0.001\right.$, partial $\left.\eta^{2}=0.32\right)$. Post hoc tests clarified the stress task elicited greater anxiety at stress exposure period 1 than that at baseline $(p<0.001)$, and greater anxiety at stress exposure period 2 than that at baseline $(p$ $<0.001)$. 
The repeated measures ANOVA for HR indicated a significant main effect for phase $\left(F[1.43,98.78]=51.59, p<0.001\right.$, partial $\left.\eta^{2}=0.43\right)$. Post hoc tests clarified HR at stress exposure period 1 were significantly higher than that at baseline $(p<0.001)$, HR at stress exposure period 2 were significantly higher than that at baseline $(p<0.001)$. Similarly, the results for RSA revealed a significant main effect for phase $(F[2.87,198.00]=51.34, p<$ 0.001, partial $\eta^{2}=0.43$ ). Post hoc tests clarified RSA levels at stress exposure period 1 were significantly lower than that at baseline $(p<0.001)$, RSA levels at stress exposure period 2 were significantly lower than that at baseline $(p<0.001)$. The results for SBP revealed a significant main effect for phase $\left(F[3.10,214.08]=33.29, p<0.001\right.$, partial $\left.\eta^{2}=0.33\right)$. Post hoc tests clarified SBP at stress exposure period 1 were significantly higher than that at baseline $(p<0.001)$, SBP at stress exposure period 2 were significantly higher than that baseline $(p<0.001)$. The results for DBP revealed a significant main effect for phase $(F[3.05$, 210.43] $=49.14, p<0.001$, partial $\eta^{2}=0.42$ ). Post hoc tests clarified DBP at stress exposure period 1 were significantly higher than that at baseline $(p<0.001)$, DBP at stress exposure period 2 were significantly higher than that at baseline $(p<0.001)$. Overall, these results confirmed that the public speaking task was highly effective in inducing subjective and physiological responses.

\subsection{Zero-order correlations}

The correlations between openness and physiological variables (change scores) at study phases are given in Table 2.

\section{INSERT TABLE 2 HERE}

Pearson correlations between openness and physiological variables revealed that 
openness was significantly positively related to baseline RSA $(r=0.32, p=0.007)$, SBP adaptation $(r=0.35, p=0.003)$, and DBP adaptation $(r=0.26, p=0.03)$. Openness was significantly negatively related to HR reactivity $1(r=-0.36, p=0.002)$, HR reactivity $2(r=$ $-0.38, p=0.001), \mathrm{RSA}$ reactivity $1(r=-0.35, p=0.003)$, RSA recovery $1(r=-0.37, p=$ $0.002)$, SBP reactivity $2(r=-0.25, p=0.04)$.

These results indicated that higher openness was associated with higher resting RSA, lesser HR reactivity, RSA reactivity, and SBP reactivity to social stress, more complete RSA recovery after social stress, and greater SBP and DBP adaptation to recurrent social stress.

\subsection{Hierarchical regression analyses}

The hierarchical regression results are presented in Table 3.

\section{INSERT TABLE 3 HERE}

The hierarchical regression analyses showed that after controlling for demographic variables (gender, age, father's monthly income, mother's monthly income, father's education level, mother's education level), openness significantly predicted HR reactivity 1 $\left(\beta=-0.32, p=0.008, \triangle R^{2}=0.10\right), \mathrm{HR}$ reactivity $2\left(\beta=-0.32, p=0.008, \triangle R^{2}=0.09\right)$, baseline $\operatorname{RSA}\left(\beta=0.29, p=0.02, \triangle R^{2}=0.08\right)$, RSA reactivity $1\left(\beta=-0.33, p=0.008, \triangle R^{2}=0.10\right)$, RSA recovery $1\left(\beta=-0.37, p=0.004, \triangle R^{2}=0.12\right)$, SBP reactivity $2\left(\beta=-0.23, p=0.04, \triangle R^{2}=0.08\right)$, SBP adaptation $\left(\beta=0.31, p=0.005, \triangle R^{2}=0.10\right)$, DBP adaptation $(\beta=0.27, p=0.03, \triangle$ $\left.R^{2}=0.09\right)$.

These results indicated that openness is a positive predictor of baseline RSA, as well as of SBP and DBP adaptation across recurrent social stress exposures; and that openness is a negative predictor of HR reactivity to first and second social stress, RSA reactivity to the first 
social stress, RSA recovery after the first social stress, and SBP reactivity to the second social stress.

\section{Discussion}

The present study examined the association between openness and physiological reactivity, physiological recovery, and physiological adaptation across two successive socially evaluative stressors. As hypothesized, it was found that higher openness was related with lesser HR reactivity to the two social stress exposures, and lesser SBP reactivity to the second social stress exposure, even after controlling for the potential influential demographic factors such as gender, age, father's monthly income, mother's monthly income, father's education level, and mother's education level. In line with the findings of Williams et al. (2009), the present study showed that higher levels of openness was related to lesser cardiovascular (HR, SBP) reactivity to socially evaluative stress. It is increasingly acknowledged that moderate cardiovascular reactivity (neither exaggerated nor blunted) is an adaptive physiological stress response pattern that is beneficial to health (Allen, 2013; Chida \& Steptoe, 2010; Manuck, 1994; McEwen, 1998, 2003, 2011; Obrist, 1976; Treiber et al., 2003; Phillips et al., 2013). In the present study, the cardiovascular reactivity of individuals with higher openness represented a relatively modest physiological response pattern, whereas the greater cardiovascular reactivity of individuals with lower openness might imply an excessive physiological response, which, if sustained, is likely to contribute negatively to psychosomatic disease processes. In addition, we found higher openness was related to higher resting RSA. Studies have shown that individuals with higher resting RSA have fewer symptoms of psychopathology (Porges, Doussard-Roosevelt, Portales, \& Greenspan, 1996) 
and decreased rates of physical illness in adulthood (Porges, 1992). Thus, the present findings suggest that individuals with higher levels of openness have higher resting RSA, might have better health outcomes. We also found higher openness was related to lesser RSA decreases (RSA withdrawals) to socially evaluative stress. It means that RSA withdrawals to socially evaluative stress in participants with higher openness is moderate, which could be conceptualized as an adaptive response profile, while RSA withdrawals to social stress of individuals with lower openness is excessive, which may reflect a maladaptive response profile. Moreover, higher openness was also found to be related with more complete RSA recovery after the first socially evaluative stress exposure. Highly efficient RSA rebound indicates adaptive physiological responding to stress and could facilitate health (Porges, 2007; Thayer \& Lane, 2000). Taken together, the present findings might suggest that individuals with higher levels of openness have adaptive social stress regulation and could achieve better health consequences.

The present study also considered physiological responses across the two successive social stressors in order to examine the relationship between patterns of physiological adaptation to repeated stress and openness. Higher openness was associated with greater adaptation (decreases) in SBP and DBP reactivity to repeated social evaluative stress. Previous studies indicated that pronounced cardiovascular adaptation to repeated stress may represent one's successful ability to cope with the adverse stimulus (al'Absi et al., 1997; Bremner et al., 1995; Frankish \& Linden, 1991; Kelsey, 1991, 1993; Kelsey et al., 1999, 2000), whereas lack of adaptation to repeated stressors may reflect an inability to adapt, and possibly lead to health problems (Hughes et al., 2011; McEwen, 1998). The present study 
extends our understanding by suggesting that physiological adaptation is more likely to occur in recurrent social evaluative stress among persons with higher levels of openness, whereas lack of physiological adaptation can been seen in individuals with lower levels of openness, a psychological trait known to be associated with ineffective social evaluative stress coping and adverse health outcomes.

Several limitations of this study should be considered with the results. First, the findings of present study were mainly relied on a sample of Chinese university sophomores. It still needs to be established whether the current findings can be generalized to a wide range of age groups with different ethnic backgrounds. Second, the present findings related to social stress and so may not be generalizable to other types of stressors (e.g., cognitive stress, emotional stress). Third, the relationship between openness and HR and RSA reactivity were observed during the first social stress exposure, while the relationships between openness and physiological adaptation to repeated social stress were only presented in SBP and DBP. Accordingly, the potential mechanisms that contribute to this response pattern of the physiological parameters should be carefully considered in future studies.

In conclusion, the findings of the present study suggested a close association between openness and physiological response profile to recurrent social stress. The results indicated that higher openness was related to lesser HR reactivity during the first and second social stress, and lesser SBP reactivity to the second social stress. Higher openness was related to higher basal RSA, lesser RSA withdrawals to the first social stress, and more complete RSA recovery after the first social stress. In addition, across the two successive social stressors, higher openness was found to be associated with pronounced SBP and DBP adaptation to 
repeated social stress. These findings might shed light on the biological basis linking openness to cardiovascular health.

\section{References}

al'Absi, M., Bongard, S., Buchanan, T., Pincomb, G.A., Licinio, J., \& Lovallo,W.R. (1997).

Cardiovascular and neuroendocrine adjustment to public speaking and mental arithmetic stressors. Psychophysiology, 34, 266-275.

Allen, M. T. (2013). Integrative commentary: Implications of blunted reactivity. International Journal of Psychophysiology, 90(2), 95-98. http://dx.doi.org/

10.1016/j.ijpsycho.2013.07.012.

Berntson, G.G., Bigger, J.T., Eckberg, D.L., Grossman, P., Kaufmann, P.G., Malik, M., \& van der Molen, M.W. (1997). Heart rate variability: origins, methods, and interpretive caveats. Psychophysiology, 34, 623-648.

http://dx.doi.org/10.1111/j.1469-8986.1997.tb02140.x.

Bibbey, A., Carroll, D., Roseboom, T. J., Phillips, A. C., \& de Rooij, S. R. (2013). Personality and physiological reactions to acute psychological stress. International Journal of Psychophysiology, 90(1), 28-36. http://dx.doi.org/10.1016/j.ijpsycho.2012.10.018.

Bremner, J.D., Southwick, S.M., \& Charney, D.S. (1995). Etiological factors in the development of posttraumatic stress disorder. In: Mazure, C.M. (Ed.), Does Stress Cause Psychiatric Illness? American Psychiatric Press, Inc, pp. 149-185.

Chida, Y., \& Steptoe, A. (2010). Greater cardiovascular responses to laboratory mental stress are associated with poor subsequent cardiovascular risk status a meta-analysis of prospective evidence. Hypertension, 55(4), 1026-1032. 
http://dx.doi.org/10.1161/HYPERTENSIONAHA.109.146621.

Connelly, B.S., Ones, D.S., Davies, S.E., \& Birkland, A. (2014).Opening up Openness: a theoretical sort following critical incidents methodology and a meta-analytic investigation of the trait family measures. Journal of Personality Assessment, 96, 17-28. http://dx.doi.org/10.1080/00223891.2013.809355.

Costa, P. T., \& McCrae, R. R. (1992). Four ways five factors are basic. Personality and individual differences, 13(6), 653-665. http://dx.doi.org/10.1016/0191-8869(92)90237-J

Čukić, I., \& Bates, T. C. (2014). Openness to experience and aesthetic chills: Links to heart rate sympathetic activity. Personality and Individual Differences, 64, 152-156. http://dx.doi.org/10.1016/j.paid.2014.02.012

Eisenstein, E.M., Eisenstein, D., \& Smith, J.C. (2001). The evolutionary significance of habituation and sensitization across phylogeny: a behavioral homeostasis model. Integrative Physiological and Behavioral Science, 36, 251-265. http://dx.doi.org/10.1007/BF02688794

Frankish, J., \& Linden, W. (1991). Is response adaptation a threat to the high-low reactor distinction among female college students? Health Psychology, 10, 224 - 227. http://dx.doi.org/10.1037/0278-6133.10.3.224

Grossman, P., Taylor, E.W. (2007). Toward understanding respiratory sinus arrhythmia: relations to cardiac vagal tone, evolution and biobehavioral functions. Biological Psychology, 74, 263-285. http://dx.doi.org/10.1016/j.biopsycho. 2005.11.014.

Haynes, S.N., Gannon, L.R., Orimoto, L., O’Brien, W.H., \& Brandt, M. (1991). 
Psychophysiological assessment of poststress recovery. Psychological Asssessment, 3, 356-365. http://dx.doi.org/10.1037/1040-3590.3.3.356.

Hofmann, S. G. (2006). The emotional consequences of social pragmatism: The psychophysiological correlates of self-monitoring. Biological psychology, 73(2), 169-174. http://dx.doi:10.1016/j.biopsycho.2006.03.001

Howard, S. \& Hughes, B. M. (2013). Type D personality is associated with a sensitized cardiovascular response to recurrent stress in men. Biological Psychology, 94, 450-455. http://dx.doi.org/10.1016/j.biopsycho.2013.09.001.

Hughes, B. M., Howard, S., James, J. E., \& Higgins, N. M. (2011). Individual differences in adaptation of cardiovascular responses to stress. Biological Psychology, 86(2), 129-136. http://dx.doi.org/10.1016/j.biopsycho.2010.03.015

James, J.E., Gregg, M.E., Matyas, T.A., Hughes, B.M., \& Howard, S. (2012). Stress reactivity and the hemodynamic profile-compensation deficit $(\mathrm{HP}-\mathrm{CD})$ model of blood pressure regulation. Biological Psychology, 90, 161-170. http://dx.doi.org/10.1016/j.biopsycho.2012.02.021

Johnson, J.A., Lavoie, K.L., Bacon, S.L, Carlson, L.E, \& Campbell, T.S. (2012). The effect of trait rumination on adaptation to repeated stress. Psychosomatic Medicine, 74(3), 258-262. http://dx.doi.org/10.1097/PSY.0b013e31824c3ef2

Jönsson, P., Wallergård, M., Österberg, K., Hansen, A. M., Johansson, G., \& Karlson, B. (2010). Cardiovascular and cortisol reactivity and habituation to a virtual reality version of the Trier Social Stress Test: A pilot study.Psychoneuroendocrinology, 35(9), 1397-1403. http://dx.doi:10.1016/j.psyneuen.2010.04.003 
Jonassaint, C. R., Boyle, S. H., Kuhn, C. M., Siegler, I. C., Copeland, W. E., \& Williams, R. (2010). Personality and inflammation: the protective effect of openness to experience. Ethnicity \& disease, 20(1), 11-14.

Jonassaint, C. R., Boyle, S. H., Williams, R. B., Mark, D. B., Siegler, I. C., \& Barefoot, J. C.(2007). Facets of openness predict mortality in patients with cardiac disease. Psychosomatic Medicine, 69, 319-322. http://dx.doi.org/10.1097/PSY.0b013e318052e27d

Kelsey, R. M., Blascovich, J., Leitten, C. L., Schneider, T. S., Tomaka, J., \& Wiens, S. (2000). Cardiovascular reactivity and adaptation to recurrent psychological stress: The moderating effects of evaluative observation. Psychophysiology, 37, 748-756. http://dx.doi.org/10.1017/S004857720098209X

Kelsey, R. M., Blascovich, J., Tomaka, J., Leitten, C. L., Schneider, T. S., \& Wiens, S. (1999). Cardiovascular reactivity and adaptation to recurrent psychological stress: Effects of prior task exposure. Psychophysiology, 36, 818-831. http://dx.doi.org/10.1017/S0048577299981672

Kelsey, R.M. (1991). Electrodermal lability and myocardial reactivity to stress. Psychophysiology, 28, 619-631. http://dx.doi.org/10.1111/j.1469-8986.1991.tb01005.x

Kelsey, R.M. (1993). Habituation of cardiovascular reactivity to psychological stress: evidence and implications. In: Blascovich, J.J., Katkin, E.S. (Eds.), Cardiovascular Reactivity to Psychological Stress and Disease. American Psychological Association, Washington, DC, pp. 135-153. 
Lang, P.J., Bradley, M.M., \& Cuthbert, B.N. (2005). International Affective Picture System (IAPS): Affective rating of pictures and instruction manual. University of Florida Center for Research in Psychophysiology, Gainesville, FL.

Lee, H.B., Offidani, E., Ziegelstein, R.C., Bienvenu, O.J., Samuels, J., Eaton, W.W., \& Nestadt, G. (2014). Five-factor model personality traits as predictors of incident coronary heart disease in the community: a 10.5-year cohort study based on the Baltimore epidemiologic catchment area follow-up study. Psychosomatics, 55, 352-361. http://dx.doi.org/10.1016/j.psym.2013.11.004

Lee, E. M., \& Hughes, B. M. (2014). Trait dominance is associated with vascular cardiovascular responses, and attenuated habituation, to social stress. International Journal of Psychophysiology, 92, 79-84. http://dx.doi.org/10.1016/j.ijpsycho.2014.03.001.

Lee-Baggley, D., Preece, M., \& DeLongis, A. (2005). Coping with interpersonal stress: Role of Big Five traits. Journal of Personality, 73, 1141-1180. http://dx.doi.org/10.1111/j.1467-6494.2005.00345.x

Lewis, G. F., Furman, S. A., McCool, M. F., \& Porges, S. W. (2012). Statistical strategies to quantify respiratory sinus arrhythmia: Are commonly used metrics equivalent?. Biological psychology, 89(2), 349-364. http://dx.doi:10.1016/j.biopsycho.2011.11.009.

Llabre, M. M., Spitzer, S. B., Saab, P. G., Ironson, G. H., \& Schneiderman, N. (1991). The reliability and specificity of delta versus residualized change as measures of cardiovascular reactivity to behavioral challenges. Psychophysiology, 28(6), 701-711. 
http://dx.doi. org /10.1111/j.1469-8986.1991.tb01017.x

Lü, W., Wang, Z., \& Liu, Y. (2013). A pilot study on changes of cardiac vagal tone in individuals with low trait positive affect: the effect of positive psychotherapy. International Journal of Psychophysiology, 88(2), 213-217.

Manuck, S. B. (1994). Cardiovascular reactivity in cardiovascular disease: “Once more unto the breach." International Journal of Behavioral Medicine, 1, 4-31.

McEwen, B. S. (1998). Protective and damaging effects of stress mediators. New England Journal of Medicine, 338(3), 171-179.

http://dx.doi.org/10.1056/NEJM199801153380307

McEwen, B. S. (2003). Early life influences on life-long patterns of behavior and health. Mental Retardation and Developmental Disabilities Research Reviews, 9(3), 149-154. http://dx.doi.org/10.1002/mrdd.10074

McEwen, B. S., \& Gianaros, P. J. (2011). Stress and Allostasis Induced Brain Plasticity. Annual Review of Medicine, 62, 431-445. http://dx.doi.org/10.1146/annurev-med-052209-100430.

Obrist, P.A. (1976). The cardiovascular behavioral interaction — as it appears today. Psychophysiology, 13, 95-107. http://dx.doi.org/10.1111/j.1469-8986.1976.tb00081.x

Pertaub, D.P., Slater, M., \& Barker, C. (2002). An experiment on public speaking anxiety in response to three different types of virtual audience. Presence Teleoperators \& Virtual Environments, 11(1), 68-78. http://dx.doi.org/10.1162/105474602317343668

Phillips, A. C., Ginty, A. T., \& Hughes, B. M. (2013). The other side of the coin: Blunted cardiovascular and cortisol reactivity are associated with negative health 
outcomes. International Journal of Psychophysiology, 90(1), 1-7.

http://dx.doi.org/10.1016/j.ijpsycho.2013.02.002

Pieper, S., \& Brosschot, J. F. (2005). Prolonged stress-related cardiovascular activation: Is there any?. Annals of Behavioral Medicine, 30(2), 91-103.

http://dx.doi.org/10.1207/s15324796abm3002_1

Porges, S.W. (2007). The polyvagal perspective. Biological Psychology, 74, 116-143. http://dx.doi.org/10.1016/j.biopsycho.2006.06.009.

Porges, S. W., Doussard - Roosevelt, J. A., Portales, A. L., \& Greenspan, S. I. (1996). Infant regulation of the vagal "brake" predicts child behavior problems: A psychobiological model of social behavior. Developmental Psychobiology, 29(8), 697-712.

Santucci, A.K., Silk, J.S., Shaw, D.S., Gentzler, A.L., Fox, N.A., \& Kovacs, M. (2008). Vagal tone and temperament as predictors of emotion regulation strategies in young children. Developmental Psychobiology, 50, 205-216.

http://dx.doi.org/10.1002/dev.20283

Saugel, B., Dueck, R., \& Wagner, J. Y. (2014). Measurement of blood pressure. Best Practice \& Research Clinical Anaesthesiology, 28(4), 309-322. http://dx.doi.org/10.1016/j.bpa.2014.08.001

Schneiderman, N., Ironson, G., \& Siegel, S. D. (2005). Stress and health: psychological, behavioral, and biological determinants. Annual Review of Clinical Psychology, 1, 607-628. http://dx.doi.org/10.1146/annurev.clinpsy.1.102803.144141

Shiner, R. L., \& Masten, A. S. (2012). Childhood personality as a harbinger of competence and resilience in adulthood. Development and Psychopathology, 24, 507-528. 
http://dx.doi.org/10.1017/S0954579412000120.

Slater, M., Pertaub, D.P., Barker, C., \& Clark, D.M. (2006). An experimental study on fear of public speaking using a virtual environment. Cyberpsychology \& Behavior, 9(5), 627-633. http://dx.doi.org/10.1089/cpb.2006.9.627

Task Force of the European Society of Cardiology and the North American Society of Pacing and Electrophysiology. (1996). Heart rate variability: standards of measurement, physiological interpretation and clinical use. Circulation, 93, 1043-1065.

Taylor, M.D , Whiteman, M.C., Fowkes, G.R., Lee, A.J., Allerhand, M., Deary, I.J. (2009). Five Factor Model personality traits and all-cause mortality in the Edinburgh Artery Study cohort. Psychosomatic Medicine, 71(6), 631-641. http://dx.doi.org/10.1097/PSY.0b013e3181a65298

Thayer, J.F., \& Lane, R.D. (2000). Amodel of neurovisceral integration in emotion regulation and dysregulation. Journal of Affective Disorders, 61, 201-216. http://dx.doi.org/10.1016/S0165-0327(00)00338-344.

Treiber, F.A., Kamarck, T., Schneiderman, N., Sheffield, D., Kapuku, G., \& Taylor, T. (2003). Cardiovascular reactivity and development of preclinical and clinical disease states. Psychosomatic Medicine, 65, 46-62. http://dx.doi.org/10.1097/00006842-200301000-00007

Turner, S.M., Beidel, D.C., \& Robertson-Nay, R. (2005). Offspring of anxious parents: reactivity, habituation, and anxiety-proneness. Behaviour Research and Therapy, 43, 1263-1279. http://dx.doi.org/10.1016/j.brat.2004.09.005

Wang, X. D., Wang, X .L., \& Ma, H. (1999). Journal of Personality and 
Social Psychologyhealth assessment scale (revised edition). Beijing: Chinese Mental Health Magazine, 205-209.

Wang, Z., Lü, W., \& Qin, R. (2013). Respiratory sinus arrhythmia is associated with trait positive affect and positive emotional expressivity. Biological Psychology, 93, 190-196. http://dx.doi.org/10.1016/j.biopsycho.2012.12.006

Westenberg, P. M., Bokhorst, C. L., Miers, A. C., Sumter, S. R., Kallen, V. L., Van Pelt, J., et al. (2009). A prepared speech in front of a pre-recorded audience: Subjective, physiological, and neuroendocrine responses to the Leiden Public Speaking Task. Biological Psychology, 82, 116-124.

http://dx.doi.org/10.1016/j.biopsycho.2009.06.005

Weeks, J. W., \& Zoccola, P. M. (2015). "Having the heart to be evaluated”: The differential effects of fears of positive and negative evaluation on emotional and cardiovascular responses to social threat. Journal of anxiety disorders, 36, 115-126. http://dx.doi.org/10.1016/j.janxdis.2015.08.004

Williams, P. G., Rau, H. K., Cribbet, M. R., \& Gunn, H. E. (2009). Openness to Experience and stress regulation. Journal of Research in Personality, 43, 777-784. http://dx.doi.org/10.1016/j.jrp.2009.06.003

Winklewski, P. J., Tkachenko, Y., Mazur, K., Kot, J., Gruszecki, M., Guminski, W., ... \& Frydrychowski, A. F. (2015). Sympathetic Activation Does Not Affect the Cardiac and Respiratory Contribution to the Relationship between Blood Pressure and Pial Artery Pulsation Oscillations in Healthy Subjects. PloS one, 10(8), e0135751.

Yang, J., McCrae, R. R., Costa, P. T., Jr., Dai, X. Y., Yao, S. Q., Cai, T. S., et al. (1999). 
Cross-cultural personality assessment in psychiatric populations: The NEO-PI-R in the People's Republic of China. Psychological Assessment, 11, 359-368. 